УДК 303.6

СЕТЕВОЙ МАРКЕТИНГ КАК СОЦИАЛЬНОЕ ЯВЛЕНИЕ

Заскалько Е. Е.

Карагандинский государственный медицинский университет: Республика Казахстан, 100000 г. Караганда, ул.

Гоголя 40 e-mail: info@kgmu.kz

Проблема сетевых взаимодействий и сетевого маркетинга рассматривается как проблема современного развитого общества. В настоящее время наблюдается рост популярности сетевого маркетинга, в том числе, на территории Казахстана. Большое количество людей начинает заниматься данным видом деятельности, примыкая к той или иной организации. Существуют причины, по которым люди начинают заниматься сетевым маркетингом: возможность приобретения товаров со скидкой, дополнительный заработок, отсутствие стартового капитала для начала такой деятельность, отсутствие давления со стороны руководства.

Влияние сетевого маркетинга на общество неоднозначно. С одной стороны, это - возможность дополнительного дохода для отдельных социальных категорий. С другой стороны, существуют проблемы, требующие дополнительного внимания, как, например, распространение медикаментов, способных нанести вред организму человека и его психике. В ходе исследования было выявлено нежелание дистрибьютеров давать информацию об особенностях их деятельности, что можно связать с неопределенностью правовой базы данного сектора в Казахстане. Дополнительное изучение и совершенствование системы сетевого маркетинга в Казахстане являются актуальными и необходимыми как для государственных и иных социальных институтов и структурных подразделений (например, медицины и здравоохранения), так и для непосредственных участников целевых взаимодействий.

Ключевые слова: маркетинг, сетевой маркетинг, сетевые продажи, сетевые сообщества, отношение к сетевому маркетингу

\title{
NETWORK MARKETING AS A SOCIAL EVENT
}

Zaskalko E.E.

Karaganda State Medical University: Republic of Kazakhstan, 100000, Karaganda, 40 Gogol st. e-mail: info@kgmu.kz

The problem of network interactions and network marketing is considered as a problem of a modern developed society. At present, there is a growing popularity of network marketing, including in Kazakhstan. A large number of people begin to engage in this type of activity, adhering to one or another organization. There are reasons why people start to engage in network marketing: the opportunity to purchase goods at a discount, additional earnings, lack of starting capital to start such an activity, lack of pressure from the authorities

The impact of network marketing on society is ambiguous. On the one hand, this is an opportunity for additional income for certain social categories. On the other hand, there are problems requiring additional attention, such as the spread of medications that can harm the human body and its psyche. The research revealed the unwillingness of distributors to provide information about the specifics of their activities, which can be attributed to the uncertainty of the legal framework of this sector in Kazakhstan. Additional study and improvement of the network marketing system in Kazakhstan are relevant and necessary for both state and other social institutions and structural units (for example, medicine and public health) and for direct participants in targeted interactions.

Keywords: marketing, network marketing, network sales, network communities, attitude to network marketing

УДК 303.6

\section{СЕТЕВОЙ МАРКЕТИНГ КАК СОЦИАЛЬНОЕ ЯВЛЕНИЕ}

В современном мире, в том числе, в независимом Казахстане, сетевой маркетинг завоевывает все большую популярность. Многие по-разному относятся к этому явлению, зачастую мнения диаметрально противоположны друг другу. Возникает вопрос о том, почему все большее количество людей начинает заниматься данным видом деятельности, какими причинами руководствуются люди, примыкая к той или иной организации сетевого маркетинга.

Проблема сетевых взаимодействий и, как вариант, сетевого маркетинга, рассматривается как проблема современного общества, преимущественно развитого индустриального и постиндустриального типов. Среди авторов - исследователей данной проблемы - Д. Белл [1], Г. Градосельская[2], Котлер[5], Б. Хасбулатова[7] и др. [3; 4; 6]. 
В настоящее время наблюдается рост популярности сетевого маркетинга (далее СМ). Большое количество людей начинает заниматься данным видом деятельности, примыкая к той или иной организации СМ. Распространение косметологических и лекарственных средств стало частым явлением в данной системе и требует особого внимания, так как отсутствие должного контроля в этой области деятельности может принести вместо ожидаемой пользы серьезный вред здоровью граждан.

Целью исследования явилось изучение практического отношения к сетевому маркетингу населения г. Караганды /Республика Казахстан. Целевой группой стали жители г. Караганды, высказавшие определенное отношение к сетевому маркетингу. Выборка составила 95 человек. Структура выборки: женщины -76,8\%, мужчины - 21,2\%; возраст респондентов: 16-17 лет - 25,2\%, 18-25 лет - 49,5\%, 25-29 лет - 4,2\%, 30-37 лет - 2,1\%, 38 и более лет $-19 \%$.

В результате анкетирования выяснилось, что в большинстве случаев, люди узнают о сетевом маркетинге из объявлений на улице, рекламы по телевизору и в интернете (60\%). Значительно реже, лишь в $32 \%$ случаев, сетевой маркетинг распространяется через коллег, друзей и представителей учебной группы (в случае студентов).

Было выявлено мнение о том, кем быть предпочтительнее, с точки зрения респондентов: быть владельцем компании сетевого маркетинга, быть распространителем продукции или быть покупателем. 63 (66,3\%) респондента считают, что лучшего всего быть владельцем бизнеса, 14 (14,7\%) - быть распространителем продукции, 18 (19\%) - быть обычным покупателем.

Ответы на вопрос о причинах, побуждающих заниматься сетевым маркетингом, показали, что на первом месте у большинства опрошенных оказалась возможность дополнительного заработка, безысходность и возможность приобретения товаров со скидкой. Интересно, что на последних позициях расположились такие причины, как приобретение новых знаний и общение с единомышленниками. В середине списка расположились стремление следовать моде, карьерный рост, повышение квалификации и возможность избежать одиночества. В процессе работы в сетевой компании человек находится в постоянном развитии, совершенствуя свои навыки общения с другими людьми, искусство убеждения, искусство продаж, а эти качества чрезвычайно ценны: специалист, обладающий такими качествами, всегда ценится намного дороже.

При ответе на вопрос «Считаете ли Вы, что в сетевом маркетинге можно заработать?» 55 человек, что составляет 57,9\%, ответили «да, возможно», значительно меньшее количество людей (20,21\%) вовсе затруднились ответить, а 7 человек (7,3\%) не считают, что 
в данной сфере можно заработать. Лишь 8 человек $(8,6 \%)$ считают, что зарабатывать таким способом можно лишь совмещая это с основным видом деятельности.

Выяснилось, что большинство опрошенных (57 человек, 60\%) безразличны к распространителям продукции сетевых компаний, 20 человек/ 21\% испытывают к ним положительные эмоции, отрицательно высказались 5 человек и резко отрицательно - 4 (Рис. 1). Преимущественно равнодушное отношение складывается из того, что сетевики в Караганде не имеют практики посещения домов, нарушения личного пространства. В то время, как, например, в США, дистрибьюторы заходят в дома и предлагают свой товар.

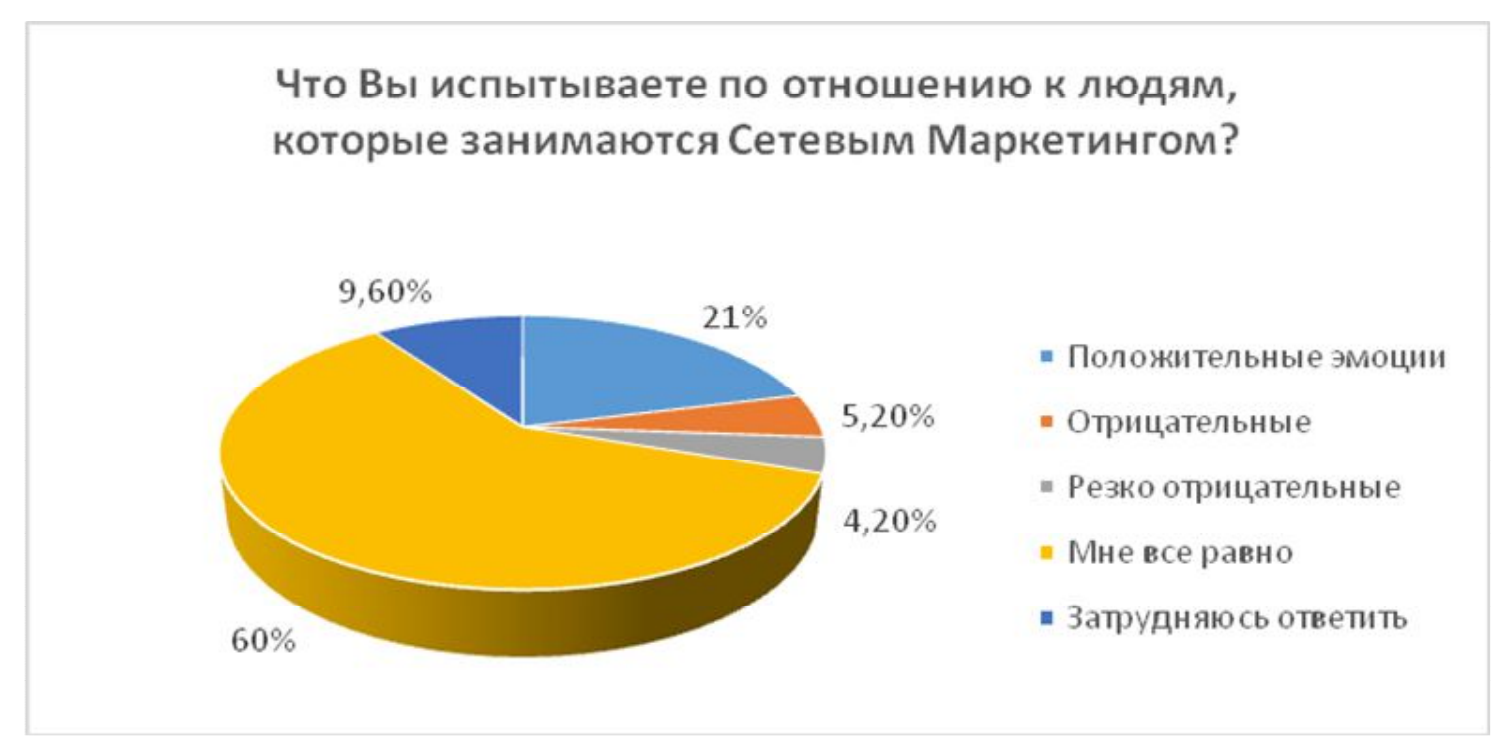

Рисунок 1

При ответе на вопрос об определении мнения о вреде или пользе сетевого маркетинга, большее количество респондентов (30 человек /31,5\%) затруднились ответить. 29 человек (31,55\%) посчитали, что СМ приносит больше пользы, чем вреда. 10 (10,5\%)-имели противоположное мнение, 24 (25,2\%)-человека категорично ответили - «только пользу», 2 (2,3\%)-«только вред» (Рис. 2).

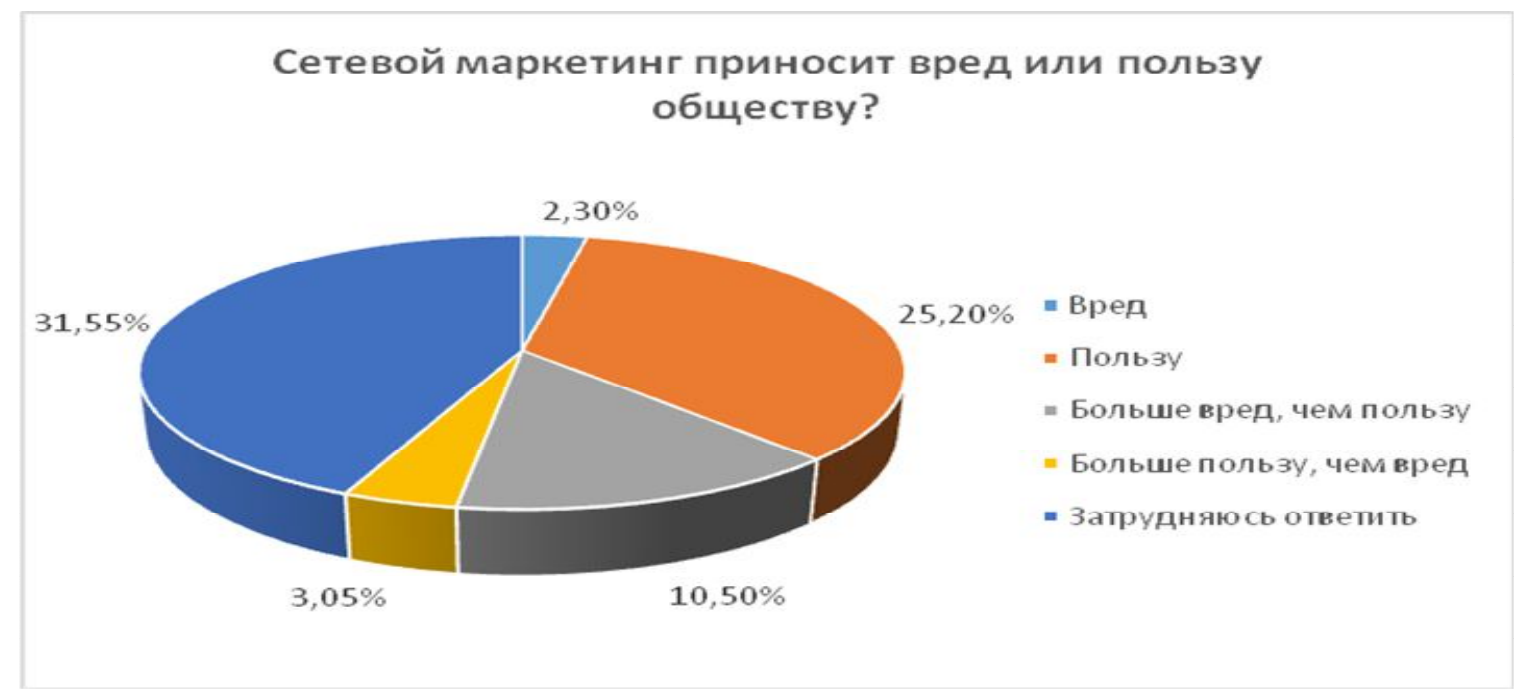

Рисунок 2 
В результате анкетирования были выявлены основные плюсы сетевого маркетинга и их компаний, по мнению респондентов (Рис.3). В большинстве своем (49 выборов) была названа возможность приобретать продукцию компаний с хорошей скидкой. Действительно, становясь дистрибьютором сетевой компании, человек получает возможность приобретать для личных нужд всю продукцию компании с хорошей скидкой (чаще всего - скидка около 20-30\%). Далее (39 выборов) - указывалась возможность использовать сетевой маркетинг как дополнительный заработок. Любая зарплата в традиционном бюджетном секторе, вне зависимости от должности, всегда ограничена, а доход в сетевом маркетинге может быть каким угодно, здесь многое зависит только от работника. «Отсутствие требований стартового капитала для начала такой деятельности» в качестве привлекательной характеристики СМ выбрали 23 раза, одинаковое количество выборов (20) получили «отсутствие давления со стороны начальства, частых стрессов и перенапряжения» и «постоянное общение с людьми и саморазвитие». В последнюю очередь респонденты выбирали возможность бесплатного обучения (15 выборов) и возможность стать членом элитного сообщества (11 выборов).

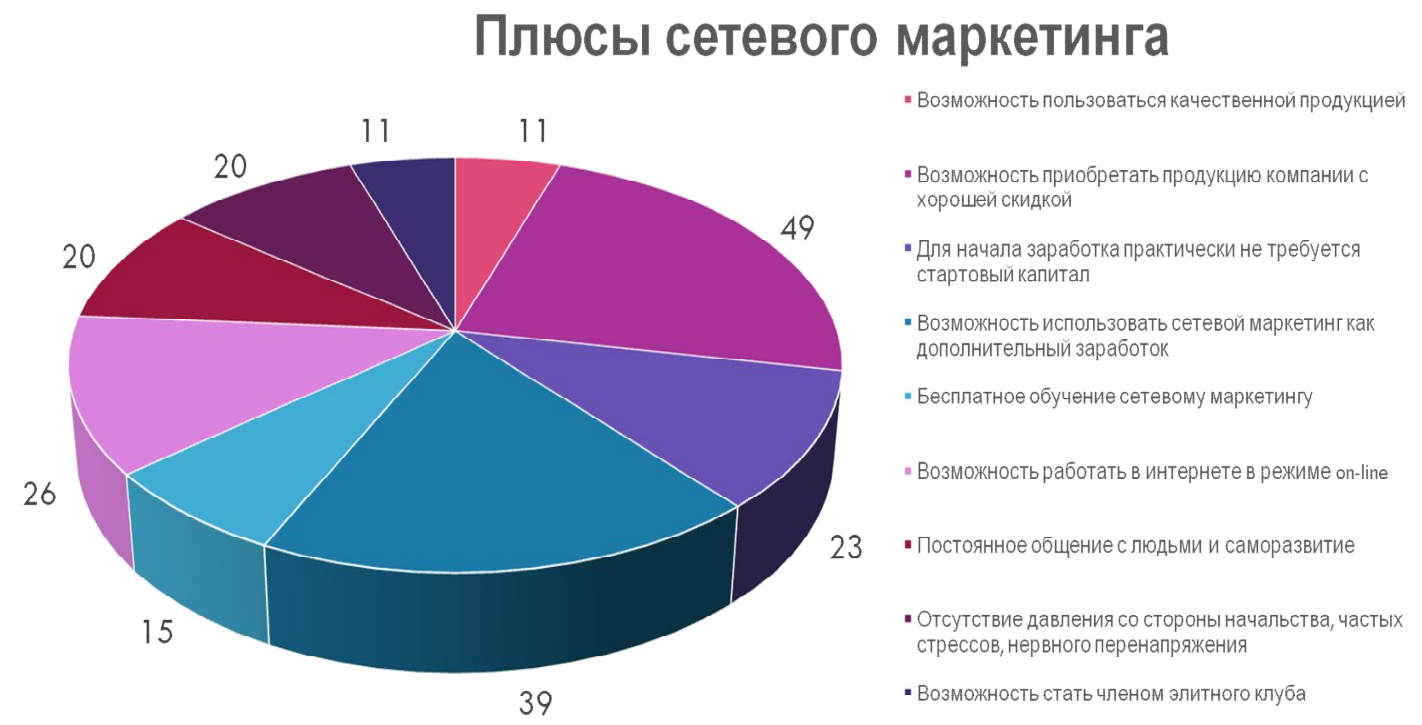

Рисунок 3

В качестве отрицательных сторон деятельности компаний сетевого маркетинга большинство респондентов (56) назвали возможность нарваться на мошенников, затем 31 опрашиваемый считает, что минусы заключаются в высокой конкуренции и негарантированном доходе, 27 раз в качестве «минуса» определили необходимость периодически покупать товары компании. Часто под видом сетевых компаний работают мошеннические структуры или финансовые пирамиды, ориентированные не на сбыт своей продукции, а на максимальную выкачку денег и быстрое сворачивание проекта. Иногда 
отличить компанию мошенника от настоящей СМ компании довольно непросто, поэтому тут необходимо обращать внимание на рейтинг, возраст, отзывы и другие факторы, характеризующие сетевую компанию (Рис. 4).

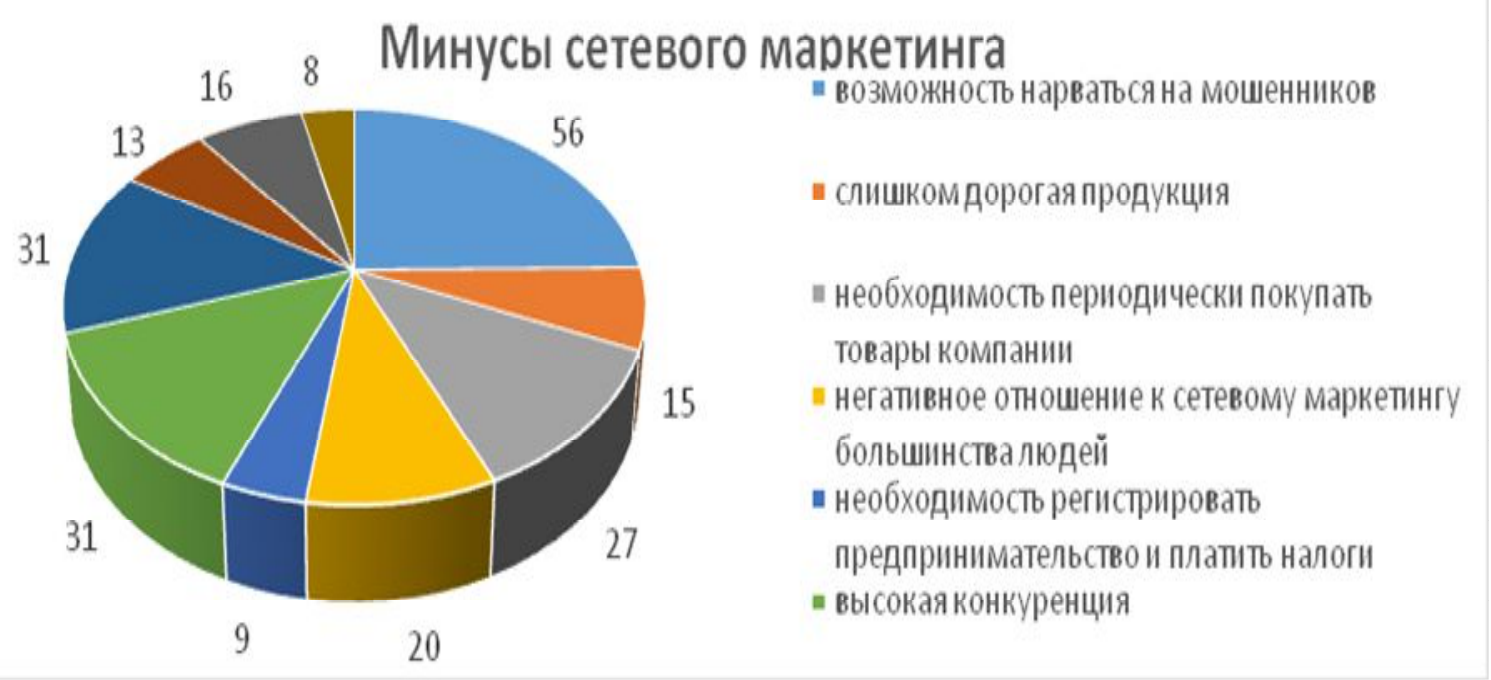

Рисунок 4

Была получена информация об известности тех или иных брендов сетевого маркетинга в Карагандинской области. Удивительно, что 40 человек не смогли назвать ни одного бренда, чаще всего назывались такие бренды, как Oriflame, Avon (Рис. 5).

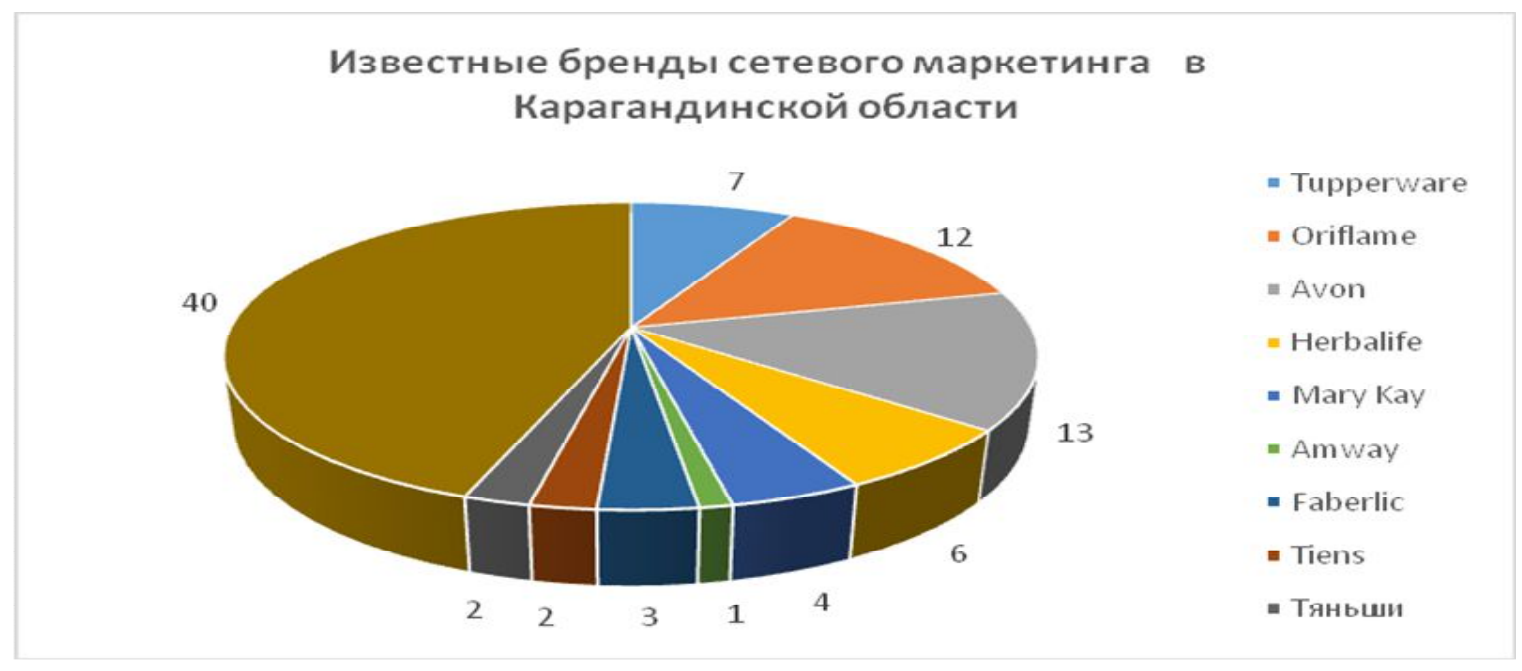

Рисунок 5

Сетевые компании на территории Республики Казахстан повсеместно стали распространяться, как результат того, что население проявляет достаточную открытость и расположенность при общении даже с незнакомцами, менее подозрительно. Поэтому осуществлять формальные контакты в странах, подобных Казахстану, гораздо легче и проще, чем даже в России. Возможно, по этой причине сетевики Центральной Азии не ощущают нехватку людей в рекрутинге столь остро, как на Западе. 
Мнение людей о роли государства в контексте темы представлено следующим образом: «не вмешиваться» (30,5\%), «регулировать» $(27,3 \%)$, «все дело в дополнительных налогах» $(15,7 \%)$, «государство должно запрещать деятельность таких организаций» $(11,5 \%)$.

При ответе на вопрос о продукции, способной нанести вред, преимущественно, а именно 45 раз, были названы лекарственные препараты, 42 раза - косметические средства, затем моющие средства и операции в финансовой сфере, далее бытовая техника и средства для уборки (Рис. 6). Основными товарами реализации обычно являются биологически активные добавки, косметические средства и другие товары широкого потребления, которые порой продают по завышенным ценам, тогда как сами товары не являются дефицитными в Казахстане. Любая схема деятельности сетевого маркетинга заинтересована только в привлечении всё большего количества участников. В конечном счёте, жертвами деятельности МЛМ-компаний становятся обычные люди, прежде всего - социально уязвимые слои населения. В Казахстане жертвами сетевого маркетинга уже стали многие, исчисляемые не единицами и десятками, а сотнями и тысячами. Хотелось бы отметить, что вопрос узаконивания сетевого бизнеса в РК стоит очень остро. Чем больше активизируется его деятельность, тем серьезнее страдают широкие слои населения. Сетевой маркетинг концепция реализации товаров и услуг, основанная на создании сети независимых дистрибьюторов, сбытовых агентов, зачастую напоминающей финансовую пирамиду, превращающийся в вид бизнеса, который якобы приносит доход, но часто основан на лжи и обмане простых граждан

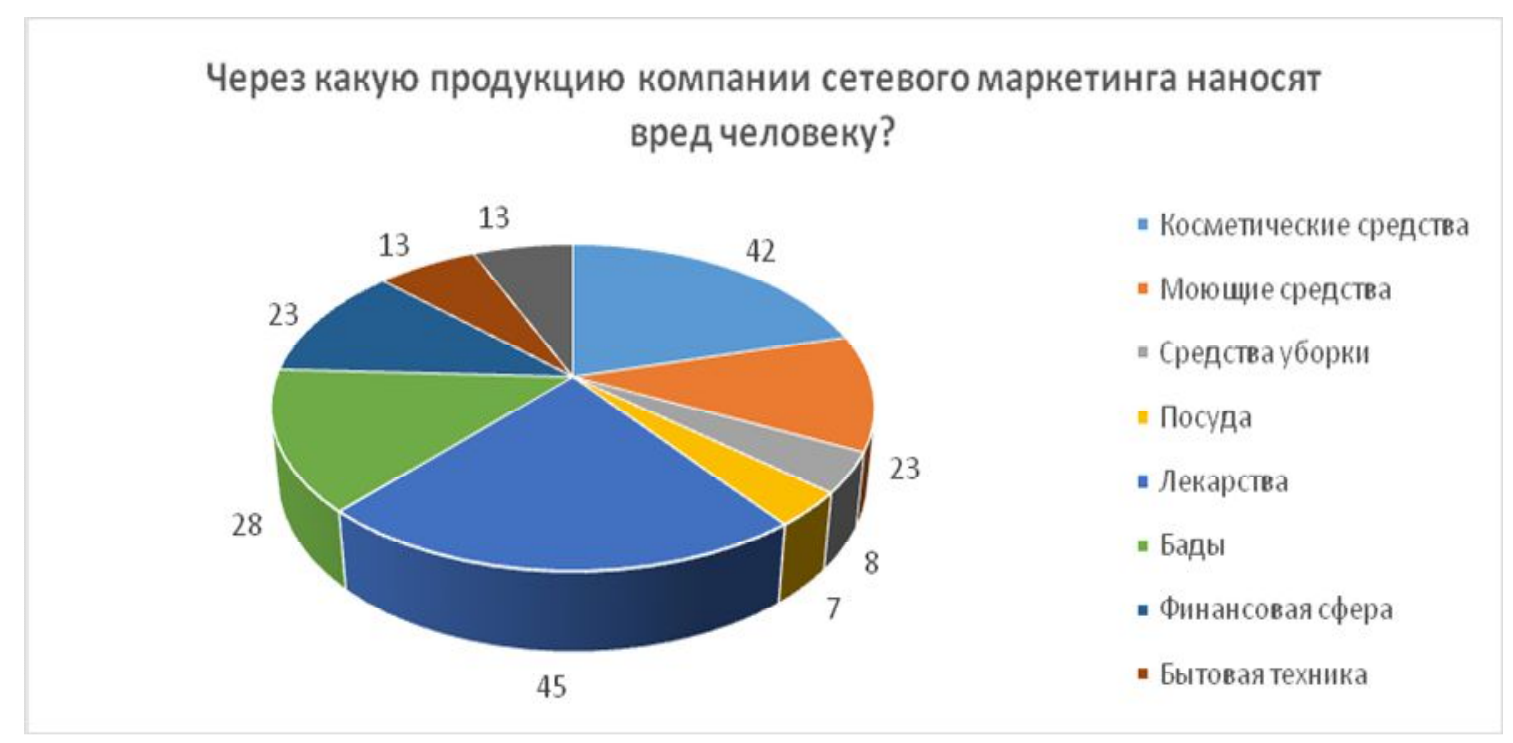

Рисунок 6

В целом положение сетевых компаний на экономическом рынке РК неоднозначно: количество сетевых компаний растет, а государственный аппарат считает, что деятельность данных компаний нужно прекратить. Когда мы говорим о пирамиде, это обозначает в 
первую очередь привлечение финансовых средств без чего-либо взамен. В случае деятельности МЛМ - компаний при правильной организации этот момент может быть исключен. Человек, внося определенный денежный ресурс, получает взамен ресурс, который можно реализовать заинтересованным в нем потребителям. Так же в ходе исследования мы столкнулись с таким явлением, как нежелание дистрибьюторов вступать в диалог по поводу их работы, и, тем более отвечать на анкеты. Не имея правовой защиты со стороны государства, дистрибьюторы довольно активно скрывают подробности своей деятельности, дабы избежать неправильной трактовки их слов и деятельности в целом.

Зачастую многие люди занимаются сетевым маркетингом, сидя дома, и не могут точно описать свою профессиональную деятельность. Вступление в «Ассоциацию деятелей сетевых продаж и маркетинга», оплата налогов и следование нормам законодательства выведет таких людей из тени и даст определенный социальный статус. Если в странах Европы и в США бизнес на дому ценится, то для казахстанцев оформление своего бизнеса, офиса, даже небольшого павильона, является более сложным мероприятием во всех отношениях. Тем не менее, рынок сетевых продаж имел и имеет большие перспективы развития во всем мире, в том числе в Казахстане, требуя специального изучения и анализа.

Сетевой маркетинг или многоуровневый маркетинг — концепция реализации товаров и услуг, которая основана на создании сети независимых дистрибьюторов (сбытовых агентов), каждый из которых, помимо сбыта продукции, также обладает правом на привлечение партнёров, имеющих аналогичные права.

К сожалению, состояние научных исследований в области сетевого маркетинга характеризуется малой проработанностью многих вопросов, относящихся к теории и практике формирования и функционирования систем распределения товаров, основанных на применении концепции сетевого маркетинга.

Дополнительное изучение и совершенствование системы сетевого маркетинга в Казахстане являются актуальными и необходимыми как для государственных и иных социальных институтов и структурных подразделений (например, медицины и здравоохранения), так и для непосредственных участников целевых взаимодействий.

\section{Список литературы}

1. Белл Д. Грядущее постиндустриальное общество. Опыт социального прогнозирования/ пер. с англ. В.Л. Иноземцева. М.М.: Akademia, 2004.

2. Градосельская, Г. В. Бизнес-сети в России [Текст] /. Г. В. Градосельская ; Нац. исслед. ун-т «Высшая школа экономики». - М. : Изд. дом Высшей школы экономики,. 2014. — 589, [3] c. 
3. Дудакова И.А. Маркетинговые стратегии экспансии торговых сетей в регионы. Вестник Чувашского университета. / [Электронный ресурc] URL: https://cyberleninka.ru/article/v/marketingovye-strategii-ekspansii-torgovyh-setey-v-region 4. Кондрашева Н.Н. Стратегия маркетинга сетевых продаж. // Проблемы экономики и менеджмента. - 2015. - №5. - С. 57-61.

5. Котлер Ф. Основы маркетинга. Краткий курс. - М.: Издательский дом «Вильямс». 2007. $-656 \mathrm{c}$.

6. Латур Б. Об интеробьективности //Социологическое обозрение. - 2007. - Т.6- №2 - С. 79-96

7. Хасбулатова Б. М., Лабунская И.А., Динева П. Развитие сетевого маркетинга в современном мире //Вопросы структуризации экономики. - 2012. - №1. - С. 163-164 